\title{
AVÓS QUE CUIDAM DOS NETOS: PERCEPÇÕES DE SAÚDE E CUIDADO DA CRIANÇA
}

\author{
Ana Helena Ferrette*, Ana Márcia Chiaradia Mendes-Castillo
}

\section{Resumo}

O objetivo da pesquisa foi conhecer as percepções dos avós que cuidam dos netos em relação ao cuidado da criança. Trata-se de um estudo qualitativo, em que 15 avós que desempenham atividades de cuidado sistemático dos netos foram entrevistados por meio de entrevistas semi-estruturadas. Os dados foram analisados por análise de conteúdo. Nos resultados, emergiram duas grandes categorias: "perspectivas sobre o cuidar", em que os avós descrevem como se relacionam com seus netos e como se sentem ao cuidarem e estarem próximos a eles durante a rotina de cuidados; e "práticas de cuidado à criança", em que caracterizamos as atividades de cuidado desenvol-vidas pelos avós em seus diversos aspectos. Consideramos que o estudo pode contribuir e subsidiar estratégias de intervenção com essa geração que tem estado cada vez mais presente no cuidado da criança, que visem a proteção, promoção e prevenção da saúde.

\section{Palavras-chave:}

Relações entre Gerações, Avós, Enfermagem Pediátrica.

\section{Introdução}

A prevalência de netos cuidados pelos avós aumentou nos últimos anos. A saída da mãe para o trabalho e problemas relacionados aos progenitores das crianças levam os avós a se tornarem cuidadores integrais de seus netos, pois, diante desse cenário, os avós são a principal escolha dos pais para cuidarem de seus filhos. 1-3 Porém, percebemos que a participação dessa geração no cuidado direto à saúde de seus netos, em nossa cultura, ainda tem sido timidamente estudada. Consideramos essencial que os profissionais de saúde acessem os conhecimentos que essa geração, agora tão presente nas famílias brasileiras, e envolvidas nos cuidados dos netos, possuem acerca de temas pertinentes ao cuidado da criança. Sendo assim, perguntamos: quais as percepções sobre o cuidado à criança que os avós que cuidam de seus netos carregam?

O objetivo do estudo foi conhecer as percepções dos avós que cuidam dos netos em relação ao cuidado da criança.

\section{Resultados e Discussão}

Trata-se de uma pesquisa qualitativa, descritiva e exploratória em que 15 avós que desempenham atividades de cuidado sistemático dos netos foram entrevistados por meio de entrevistas semi-estruturadas contendo três perguntas norteadoras. Os participantes foram recrutados mediante a técnica snow ball sampling, conhecida no Brasil como "amostragem em Bola de Neve". 4 Os dados foram analisados por análise de conteúdo e trouxeram as percepções dos avós que cuidam dos netos em relação ao cuidado da criança, emergindo duas grandes categorias descritas na tabela a seguir:

Tabela 1. Categorias das percepções dos avós que cuidam dos netos em relação ao cuidado da criança

\begin{tabular}{l|lr|}
\multicolumn{2}{c|}{$\begin{array}{c}\text { Perspectivas sobre o } \\
\text { cuidar }\end{array}$} & \multicolumn{2}{c|}{$\begin{array}{c}\text { Práticas de cuidado à } \\
\text { criança }\end{array}$} \\
\hline $\begin{array}{l}\text { Descrição de como os avós } \\
\text { se relacionam com seus }\end{array}$ & $\begin{array}{l}\text { Caracterização das } \\
\text { atividades de cuidado } \\
\text { netos e com os demais } \\
\text { desenvolvidas pelos avós } \\
\text { integrantes da família, }\end{array}$ & em seus diversos \\
\hline
\end{tabular}

\begin{tabular}{ll|l|} 
como se sentem ao & aspectos: alimentação, \\
cuidarem e estarem & higiene, sono, cuidados \\
próximos a eles durante a & em situação de doença, \\
rotina de cuidados, e quais & acompanhamento \\
são suas fontes de suporte & médico, educação, lazer \\
e de busca de informações. & e brincadeiras.
\end{tabular}

\section{Conclusões}

O estudo reforçou a realidade de que os avós convivem com as crianças em boa parte da semana e lidam com diversas questões dentro de sua criação, passando pelos cuidados com a saúde, mas também se envolvem no acompanhamento escolar e nas preocupações sobre a educação deles; lidam com diversos sentimentos em relação aos seu filhos e netos; estão sempre conhecendo novas formas de cuidar que diferem das que usaram no passado; e ainda, se utilizam da mídia, meios de comunicação, profissionais da área e seus próprios filhos como fontes de suporte em caso de dúvida. Dessa forma, a pesquisa pode contribuir e subsidiar estratégias de intervenção com os avós que visem a proteção, promoção e prevenção da saúde, criando práticas educativas para auxiliá-los no cuidado à saúde de seus netos, como grupos de avós em Centros de Saúde (Unidades Básicas de Saúde) e incentivar a criação de iniciativas nacionais com cursos e orientações online e presenciais para esse público.

\section{Agradecimentos}

Agradeço a $\operatorname{Prof}^{a}$ Dr $^{\mathrm{a}}$ Ana Márcia Chiaradia MendesCastillo e a todos que contribuíram e ajudaram na realização desse trabalho. $O$ estudo foi fomentado pela bolsa de Iniciação Científica do Programa Institucional de Bolsas de Iniciação Cientifica concedida pelo Conselho Nacional de Desenvolvimento Científico e Tecnológico.

\footnotetext{
1 Araújo CP, Dias CMSB. Avós guardiões de baixa renda. São João del-Rei Pesqui Prát Psicossociais. 2010; 4(2): 229-37.

${ }^{2}$ Lopes ESL, Neri AL, Park MB. Ser avós ou ser pais: Os papéis dos avós na sociedade contemporânea. Textos Envelhecimento. 2005; 8(2): 30-2.

3 Oliveira ARV, Gomes L, Tavares AB, Cárdenas CJ. Relação entre avós e seus netos no período da infância. São Paulo: Rev Kairós Gerontol. 2009; 12(2): 149 58 .

${ }^{4}$ Goodman L. Snowball Sampling. In: Annals of Mathematical Statiscs; 1961 [citado em 2018 Mar 20]; 32(1): 148-170.
} 